\title{
Politieke mag, die Ou Testament en kerkeenheid
}

J H le Roux

\section{ABSTRACT}

Political power, the Old Testament and church unity

The family of Dutch Reformed Churches in South Africa are involved in tense discussions on church unity. One aspect which must be discussed thoroughly is the legitimation of political power. Not only in the past but also the present Mandela government is religiously supported. It is argued that this a dangerous venture. Some examples from the Old Testament are used to illustrate this point. It is stated that Israel became disillusioned in political power and therefore reformulated royal theology.

\section{INLEIDEND}

Oor die voorgenome kerkeenheid en die totstandkoming van 'n nuwe Nederduitse Gereformeerde Kerk word veel gepraat. Dit is hierdie skrywer se bede dat kerkeenheid spoedig op grond van historiese redes sal plaasvind. In die proses van eenwording moet daar egter ruimte vir indringende gesprek oor krapperige sake geskep word. Sake wat werklike eenheid eerder belemmer as bevorder. Een is die naïf-fundamentalistiese Skrifgebruik. Anders gestel: die vermyding van die kritiese Bybelwetenskap. Op allerlei maniere het ons die invloed van die negentiende eeuse Bybelwetenskap gesystap en verdag gemaak ${ }^{1}$. En ons teologie toon dit - veral ook die gesprekke oor kerkeenheid. 'n Tweede saak is die simplistiese omgang met die geskiedenis. Van 'n kreatiewe omgang met die apartheidsverlede waarin die veelkantigheid van die probleem blyk, word weinig verneem ${ }^{2}$.

En dan die probleem van mag, politieke mag. Oor mag en die religieuse legitimering daarvan moet 'n Verenigde Nederduitse Gereformeerde Kerk indringend gesels. Hulle wat nog nooit mag gesmaak het nie, moet leer by hulle wat dit ken. Hulle moet hoor wat mag aan mense doen en godsdiens se legitimeringsfunksie verstaan. Hulle wat nog altyd magteloos gevoel het, moet luister na hulle wat deur mag verinneweer is. Politiek en politici het nog altyd na die kerk as legitimeringsinstansie opgesien. Godsdiens se ondersteunende rol was nog altyd noodsaaklik. Daarom dan hierdie artikel oor mag. Eers word die 
"teologiese eksperiment" waarmee ons besig is, verduidelik. Dan iets oor ons Suid-Afrikaanse konteks. Vervolgens word die grootste gedeelte van die artikel aan sommige Ou-Testamentiese perspektiewe gewy. Ten slotte volg enkele slotopmerkings.

\section{2 'N TEOLOGIESE EKSPERIMENT}

In 'n sekere sin is hierdie artikel 'n eksperiment. Dit sluit by Rainer Albertz se onderskeiding tussen godsdiensgeskiedenis en Ou-Testamentteologie aan ${ }^{3}$. Albertz se godsdiensgeskiedenis bly 'n opwindende leeservaring en hierdie onderskeiding uiters interessant. Aangesien elders 'n artikel oor Albertz se werk sal verskyn ${ }^{4}$, word sy voorkeur vir 'n godsdiensgeskiedenis slegs hier vermeld.

Albertz maak ' $n$ besliste keuse vir 'n godsdiensgeskiedenis. Dit is bo 'n Ou Testament teologie te verkies. Hy voer onder andere die volgende redes aan: 'n godsdiensgeskiedenis laat meer reg aan die historiese aard van die Ou Testament geskied; dit belig die noue band tussen religieuse uitsprake en lewens- of ontstaanskonteks beter; dit laat meer reg aan die dialogiese proses, die gesprek tussen die verskillende teologiese tradisies (binne die Ou Testament) geskied; dit slaag meer daarin om Israel binne 'n baie breër Ou Nabye Oosterse konteks te plaas.

'n Ou Testament teologie het natuurlik ook 'n plek. Dit bly nog steeds ' $n$ belangrike dissipline binne die Ou-Testamentiese wetenskap. Maar dan moet 'n teologie sy plek ken. Dit moet as ' $t$ ware nie probeer heers nie, maar moet eers op 'n godsdiensgeskiedenis volg. Met vandag se brandende kwessies as uitgangspunt kan 'n teologies-tematiese dwarssnit uit die godsdiensgeskiedenis gemaak word. Vanuit ons tyd kan na 'n "oplossing" in Israel se tyd gesoek word. 'n Teologie volg nie net op 'n godsdiensgeskiedenis, maar reflekteer ook die teoloog se tyds.

Dit is presies wat ek in hierdie artikel wil doen. Aan die hand van godsdienshistoriese insigte (veral van Albertz) wil ek poog om iets van Israel se teologiese hantering van politieke mag te verstaan. Legitimering van politieke mag in Suid-Afrika vorm dus die beginpunt van ons studie. Van hieruit word die Ou Testament as 't ware ondervra. Godsdienshistoriese insigte word dan gebruik om gestalte aan ons probleem te gee. Ons let byvoorbeeld op die kwistige legitimering van mag tydens die konings asook op die geweldige reaksies daarteen. Voordat ons egter daarby kom, eers iets oor die probleem: politieke mag en godsdiens in Suid-Afrika. 


\section{MAG, DIE LEGITIMERING DAARVAN EN DIE NUWE SUID-AFRIKA}

Politiek is mag. Alles draai om magspeletjies. Maatskaplike en politieke ideale word ook nagestreef en daarvoor is mag onontbeerlik. Magsvermeerdering is nodig om andere te manipuleer en (selfsugtige?) doelwitte na te streef. Geen politiek kan daarom sonder mag, dwang of geweld nie ${ }^{6}$. Tot 'n groot mate verdring politieke mag die mens: dit slurp jou in, dwing jou tot deelgenootskap, omvorm jou denke sodat dit by die staat inpas, maak jou soos die ander partygenote, duld nie weerstand nie, moedig nie kritiese denke aan nie. Teen wil en dank word die individu en die groep by 'n bepaalde politieke denkraamwerk ingesleep. Mag kan 'n mens ook wegstoot en uitsluit, marginaliseer en passiveer.

In hierdie land se veelbewoë geskiedenis het verskillende mense verskillende gestaltes van mag ervaar. Vroeër het swartmag witmag ervaar en baie negatief daarop gereageer. Tans voel die witgroep die mag van swartdemokrasie: rekonstruksie van die samelewing, miskenning van taalregte, redusering tot 'n minderheidstatus, implementering van regstellende aksie, eensydige interpretasies van die verlede, manipulering van 'n skuldgevoel, toenemende beheer oor elektroniese media, ensovoorts. Swartmag het 'n werklikheid in Suid-Afrika geword.

En die nuwe regeerders soek legitimasie vir hulle doen en late. Veral die kerk en die godsdiens word netjies hiervoor ingespan. 'n Hele woordeskat het ook ontstaan om hieraan uitdrukking te gee. Woorde soos "geregtigheid", "versoening", "medemenslikheid", "volledige demokrasie", "agtergeblewene", “ontmensliking", "transformasie", "regstellende aksie", "heropbou", "reënboognasie" en nog talle meer word telkens gebruik. Hiermee word 'n breë religieuse begronding van die gebeure in Suid-Afrika verleen. Alhoewel die diskoers nie oral en altyd dieselfde verloop nie, vertoon dit tog sekere kenmerke. Eers word die oue afgekraak: apartheid is sonde en selfs kettery. Alles wat tydens die voorMandela-era gebeur het, is verkeerd, onmenslik en daarom verwerplik. Vervolgens word die nuwe Suid-Afrika aangeprys. In die herfs van 1994 het geregtigheid ten einde laaste geskied en het volle demokrasie aangebreek. God se hand is in alles gesien en met dankbaarheid so aanvaar. Mense (veral wittes!) moet hulle net sosiaal, polities en religieus laat transformeer en so deel van God se reënboognasie word. Versoening en nogmaals versoening bly egter die noodsaaklike voorwaarde vir 'n verenigde nasie. Onder andere sluit dit 'n belydenis van die apartheidsondes in. Eers wanneer dit gebeur, sal van ware versoening sprake wees. 
Eers dan kan die heropbou van die land en die ontwikkeling van sy mense plaasvind.

So effektief was die religieuse legitimering van sowel die voorMandela-struggle as die Mandelaregering dat ongelooflik veel in 'n kort tydjie bereik is. Ongekende buitelandse steun het gevolg en Suid-Afrika staan in die sentrum van belangstelling. Binnelands is ook veel bereik. Wittes en veral regse groeperinge is so gepassiveer dat van verset weinig sprake is. 'n Belangrike rede hiervoor is die religieuse en morele begronding van die ANC-regering. Hierdie koppeling tussen mag en godsdiens kan mettertyd suur word en daarom die onderstaande bespreking.

\section{POLITIEKE BEVRYDING EN 'N EGALITARIESE SAME- LEWING}

In Egipte het Jahwe Israel se nood gesien, 'n leier (Moses) gestuur en nuwe lewensmoontlikhede geopen. Jahwe se optrede was meer polities van aard: $\mathrm{Hy}$ het in 'n bestaande staats- en samelewingstelsel ingegryp en onderdruktes verlos. Hy het die nood van politieke nooddruftiges raakgesien en gehelp ${ }^{7}$. So anders was sy optrede in die aartsvaderera. Toe is 'n El-tipe God aanbid: Hy het met die familie of dan die enkeling erns gemaak en hulle met die klein dingetjies van menswees (soos kos, klere, vrugbaarheid) gehelp ${ }^{8}$. In Egipte leer Israel Jahwe anders ken. Hy is nou die Een wat vir die groot groep intree en hulle politieke Bevryder word.

Israel se bevrydingservaring het tot 'n bepaalde tipe samelewing aanleiding gegee. Anders gestel: Israel wou aan hulle besondere ervaring ' $n$ bepaalde gestalte gee. Na die besetting van en vestiging in die "beloofde land" het daar 'n heel besondere samelewing ontstaan'. Geloof in Jahwe is as ' $t$ ware in sosiale terme oorgesit en boeiend was die nuwe samelewing wat ontstaan het. Geen staatsmag is geduld nie en die samelewing was oop en vry. Belastings is nie gehef nie en aan staatsamptenare was geen behoefte nie. Sentrale politieke mag het ontbreek en net soveel mag as wat vir die welsyn van die gemeenskap nodig is, is toegelaat. Permanente militêre leiers was onnodig en van gevestigde politieke- en staatsmag was daar geen sprake nie. Indien gevare gedreig het, het Jahwe 'n leier geskenk. Nadat die gevaar afgeweer is, het hy weer na sy vorige beroep teruggekeer. In hierdie gemeenskap het optimale vryheid geheers en was gemeenskapsoptrede vrywillig ${ }^{10}$.

Ten grondslag hiervan was 'n besondere siening van die Jahwe: Hy was die Bevryder uit politieke dwingelandy, daarom was die nuwe 
gemeenskap vry, oop en gerig teen enige vorm van oorheersing. Hierdie faset is so belangrik dat ons dit weer wil herhaal. Israel se ervaring met Jahwe in Egipte en die woestyn het tot 'n spesifieke soort samelewing aanleiding gegee. Daarin is alle mag gedesentraliseer en het 'n antiheersers-samelewing tot stand gekom. Omdat Jahwe oor alle mag beskik en teokraties oor die gemeenskap regeer, is die uitbuiting van mag gestuit en alle ongebreidelde magsaanwending effektief gesmoor ${ }^{11}$.

\section{DIE DILEMMA VAN 'N BEVRYDINGSBEWEGING}

'n Bevrydingsbeweging sit altyd met een groot dilemma: verlossing van onderdrukkende politieke strukture bevredig nie op die lange duur nie. Blote vryheid van onderdrukking is onvoldoende. Iets meer is nodig: mag, politieke mag. Dit is juis die probleem: bevrydes skep opnuut weer neerdrukkende politieke strukture. Politiek dwing mense en duld nie veel teenstand nie. Dit is presies wat met Israel gebeur het. Vanaf die koningstyd het Israel die skerpkant van mag begin ervaar ${ }^{12}$. Staatsmag wat die eie mag net verder koester en uitbrei; politieke mag wat alles vir eie voordeel manipuleer; militêre mag wat alles platloop wat die eiebelang bedreig; ekonomiese mag wat die ryke bevoordeel en die arme aan sy lot oorlaat; sosiale mag waarin die egalitariese deur 'n elitistiese samelewing verruil is.

Mag het die Israelitiese samelewing radikaal verander. Nuwe instellings, nuwe gesagsfigure en 'n ander tipe landsburger het te voorskyn getree. Omtrent niks van die ou era het oorgebly nie. Ons let op enkele voorbeelde ${ }^{13}$. 'n Permanente weermag met permanente lede het ontstaan. Soldaatwees was nie meer 'n tydelike saak nie, maar 'n heeltydse beroep. Heilige oorloë was vir goed verby. Oorloë was nie meer net defensief nie. Soldate het nie meer net die nood afgeweer en dan huiswaarts gekeer nie. Oorlog het deel van ' $n$ magspel geword. Dit is gevoer met die doel om te oorwin en te heers. 'n Magtige staatsdiens het ontwikkel. Staatsamptenare moes die staat op verskillende vlakke dien. Vir belastingsdoeleindes het Salomo sy jong staat in verskillende distrikte verdeel en moes verskillende amptenare die geld invorder. Dít was 'n geweldige ingrype in die gemeenskap. Tot nog toe was belasting nie gevorder nie, maar die nuwe staat het daarop aangedring. En wie nie wou meedoen nie, is hardhandig hanteer. Tydens Salomo se bouwerke was daar 'n voortdurende tekort aan arbeiders. Links en regs het hy toe mense opgekommandeer. Mense is selfs gedwing om met die tempelbou te help. Hierdie dwangarbeiders was egter magteloos en moes maar voor die sterk staatsgesag buig. Groot 
bitterheid het mettertyd hieruit voortgevloei en die uiteindelike gevolg was die skeuring van die ryk na Salomo ${ }^{14}$.

\section{JAHWE MOES BY DIE STAATSMAG INPAS}

Mag, veral staatsmag roep om legitimering. Koning en amptenaar se dade soek voortdurende ondersteuning. Gedurende die vorige rigtersera was dit makliker. Jahwe het self 'n leier ('n rigter) vir 'n spesifieke taak aangewys en dit was voldoende. Alles het egter nou verander. Magsfigure en magspolitiek het te voorskyn getree en hiervoor was legitimering broodnodig. Godsdiens moes die sisteem in stand hou. Ons moet eerder sê: op ' $n$ massale manier is mag in Israel deur godsdiens gerugsteun. Om dit te bewerkstellig, is die Jahwegeloof teen sy gryn gebuig om die Dawidiese koningskap te akkommodeer en te legitimeer. Watter magte en voorregte het die koning darem nie gekry nie.

Hy het sommer Israel se plek ingeneem: Dawid en sy nageslag sou die sentrale plek in die verhouding met Jahwe inneem; alles sou om die koning en Jahwe wentel. Jahwe het aan Dawid 'n dinastie beloof: uit sy geslag sou daar altyd iemand op die troon sit; die Dawidshuis het hiermee Goddelike usansie ontvang; Jahwe sou Hom ewiglik aan 'n bepaalde koningshuis verbind. Hierdie Dawidsverbond was onvoorwaardelik: al sou Dawid of sy seuns verkeerd doen, sal Jahwe steeds trou aan die Dawidshuis bewys. Onder alle omstandighede kon die Suidryk op Jahwe se hulp reken. Konings het oor enorme mag beskik: alle koningsmag was deur Jahwe gesanksioneer. Sonder teenspraak kon hy sy septer oor die politiek, weermag, ekonomie, ensovoorts swaai. Al sy magsdade het Goddelike goedkeuring gedra. Dawidiese konings het deel aan Jahwe se wêreldregering gekry: die koning het as 't ware by Jahwe se wêreldprogram ingeskakel. Jahwe het die wêreld deur die konings regeer. Konings was Jahwe se "agente" waardeur sy beheer uitgebrei is. Konings was die middelaar tussen Jahwe en die volk: deur die koning word die volk geseën. Hy is die waarborg vir die vrugbaarheid van en stabiliteit in die land. Regshulp was 'n belangrike kenmerk van die Dawidiese koning. Hy moes die regspleging waarborg. Hy was veronderstel om reg aan die wees en die weduwees, die swakkes en die verontregtes te verleen. Oor priesters en profete het konings ook 'n sê gehad: Dawid het priesters soos Sadok en Abjatar aangestel en profete het mettertyd deel van die staatshuishouding geword. Sowel paleis as godsdienstige leiers het baie naby aanmekaar gekom. 'n Koning het ook priesterlike funksies gehad: by die altaar en tydens feesdae het die koning sekere take vervul. Tipies van die Dawidiede 
was die usurpansie van die staatskultus: die tempel was die koning se eiendom en was op dieselfde perseel as die paleis geleë. Die tempelkultus was die koning en staatsbelange ten dienste en tempelkultus is in staatskultus verander ${ }^{15}$.

\section{JESAJA: POLITIEK EN GELOOF IS EINTLIK ONVERENIG- BAAR}

Jesaja was die eerste wat 'n wig tussen Jahwe en politieke mag ingedryf het $^{16}$. Daaglikse politieke besluite kan geen geloofsaansprake ernstig neem nie. Geloof is ook weer so andersoortig dat dit net nooit in die politiek kan tuis wees nie. Veral het dit in Jesaja se bediening sedert 734 vC geblyk. Peka van die Noordryk en Resin van Damaskus het teen die Suidryk opgetrek (Jes 7:1-9)17. Hulle wou Agas in 'n anti-Assiriese koalisie dwing. Spanningsvolle tye het gevolg en vir Jesaja was daar slegs een uitweg: geloof. Agas moes net in Jahwe glo en dan sou die aanslag afgeweer word. Vir Agas was dit uiteraard geen goeie politiek nie. Net te veel was op die spel: die inmenging van 'n wêreldmag, ekonomiese oorlewing en die eie staat se voortbestaan. Fyn politieke voetwerk en skerp militêre oorleg was nou nodig. Geloof het net nie gepas nie. Daarom volg Agas ook nie hierdie weg nie. Hy onderwerp hom vrywilliglik aan die Assiriese mag. Daardeur het hy die veiligheid van sy koninkryk verseker. Alles het egter teen 'n hoë prys geskiet. Hy moes silwer en goud wat in die huis van die Here en in die skatkamers van die paleis was, vat en as geskenk aan die koning van Assirië stuur (2 Kon 16:5-8) ${ }^{18}$.

$1 ;$

Baie jare later het dieselfde met Hiskia gebeur. Toe hy van Sargon se dood in $705 \mathrm{vC}$ verneem het, wou hy onmiddellik sy vasalstatus afskud. In der haas is alliansies met Egipte en Babilonië aangeknoop, en is 'n sterk anti-Assiriese politiek gevolg. Alles was natuurlik pogings om die Assiriese wurggreep op die Suidryk te verminder. Jesaja was hierteen gekant. Alliansiepolitiek en 'n wapenopbou het eerder op 'n gebrek aan Godsvertroue gedui. Te midde van hierdie politieke druk stel Jesaja sy bekende eis: "Julle krag lê in stil wees en vertroue hê" (Jes 30:15). Vertroue impliseer die aflê van allerlei politieke en militêre magspeletjies. Weer eens is die profeet se woorde in die wind geslaan. Eintlik kon dit ook nie anders nie. Magspolitiek maak nie ruimte vir stilwees en geloofsvertroue nie. Magspeletjies moet met die fyn instrumente van politieke en militêre vernuf beoefen word. Daarom pas Jesaja se woorde ook nie eintlik nie. Geen wonder dat Hiskia dit nie kon navolg nie ${ }^{19}$.

In $701 \mathrm{vC}$ het Sanherib Palestina binnegeval en volgens Assiriese bronne byna ses en veertig Judese stede verwoes. Jerusalem se einde was 
in sig. Hiskia het "polities korrek" opgetree deur Sanherib dringend te laat weet: "Ek het verkeerd gedoen. Trek u terug, ek sal betaal wat u vra". Alles het natuurlik teen 'n prys geskiet: Sanherib het Hiskia "met iets meer as tien ton silwer en een ton goud" beboet. Onder andere moes die tempel en die paleis se skatkamers gestroop word (2 Kon 18:13-16). Op die kort termyn kon Hiskia sy staat red, maar op die lange duur kon Jerusalem nie die groot magte weghou nie.

Vir die eerste keer in Israel se godsdiensgeskiedenis is ' $n$ wig tussen Jahwe en die staatsmag ingedryf. Koning en magselite kon Jahwe nie meer vir eie politieke en militêre magspeletjies opeis nie. Jahwe was nie meer vanselfsprekend aan die koning se kant nie en het ook nie meer staatsoptrede gesteun nie. 'n Belangrike korrektief op die koningsteologie is aangebring: koninklike en goddelike mag is geskei. Jahwe regeer nie meer deur die Jerusalemse koning nie. Hy is nog by politieke mag betrokke, maar tree baie meer "onafhanklik" van die Dawidiese koning $\mathrm{op}^{20}$.

\section{HOSEA: DEUR MAG HET ISRAEL VERWORD}

Ongenaakbare magspolitiek het Hosea laat vasskop. Dít het Israel se wese aangetas. Israel was anders as die ander volke, want hulle God was so totaal anders 21 . Deur 'n historiese gebeurtenis het Jahwe Israel vir Homself toegeëien. Hulle identiteit is deur 'n historiese daad gekonstitueer: "Ek is die Here jou God van die tyd van Egipte af" (Hos 12:10; 13:4). Magspeletjies het egter alles in gevaar gestel. $\mathrm{Na}$ die guns van die groot magte is gesmag: "En tog het die leiers by Assirië gaan hulp soek. Efraim is soos 'n eensame wildedonkie; hy het vir homself vriende gaan soek" (Hos 8:9). Verdrae is gesluit en ook weer verbreek: "Hulle praat net, hulle maak valse beloftes, hulle sluit verdrae" (Hos 10:4). Alliansiepolitiek het Israel se besondere aard ondermyn. Hulle het van Jahwe se liefde begin vergeet; hulle het Jahwe se verbond ondergeskik aan magspolitiek gestel ${ }^{22}$. Die ergste is dat Israel se sug na die groot magte nie hulle lot kon verander nie. Politieke mag kon hulle nie teen die Assiriërs help nie. Eers moes hulle alle mag verloor om hulle eie aard te kon ontdek. Soos in die woestyn moes hulle deur die Assiriese oorwinning opnuut gevorm en geslyp word, moes hulle opnuut vertroue in Jahwe leer ${ }^{23}$. 


\section{DEUTERONOMIS: POLITIEKE MAG WORD DRASTIES BEPERK}

Kort voor die Judese einde (in $586 \mathrm{vC}$ ) is daar intensief oor die samelewing nagedink. Op verskillende maniere het die Deuteronomistiese beweging ingrypende veranderinge in die gemeenskap voorgestel. Een daarvan het met die koning te make gehad. Alles dui op 'n totale ontnugtering met die heersers en die magsmaneuvers van die koning en sy amptenare. Daarom is die koning nou heeltemal "ontwapen" en die klassieke koningsteologie op sy kop gekeer.

Alhoewel nog deur Jahwe verkies, is die koning geheel en al van sy magte en voorregte gestroop. Hy word trouens 'n hele aantal sake verbied. Talryke strydwaens was verbode sodat hy nie 'n militêre magsbasis kon opbou nie. Geen militêre of politieke bondgenootskappe met Egipte kon gesluit word nie. Om baie vrouens te hê was ook verbode, want dit kon net tot allerlei vorme van sinkretisme lei. Verder het die koning ook nie meer goeie regspraak gewaarborg nie. Selfs die reg om regters aan te stel, is hom ontneem (Dt 16:18). Verder was hy nie meer die "heilsmiddelaar" nie. Jahwe se seën en heil was nie meer van die peroon en werk van die koning afhanklik nie. Ten slotte was die koning nou net die primus inter pares (vgl 17:15). Daarom sou hy sy onderdane "broers" noem ${ }^{24}$.

Iets soortgelyks word by die profeet Esegiël bemerk ${ }^{25}$. Toe hy tydens die ballingskap oor Israel se heropbou en ontwikkeling besin het, moes hy ook oor politieke mag nadink. Wat sou die toekoms van politieke magsfigure wees? Esegiël het die koning geheel en al ontmagtig en sy pligte radikaal ingekrimp. Trouens, daar sou nie weer 'n koning wees nie. Net 'n soort van 'n vors. Volgens Esegiël moes die land herverdeel word. Al die stamme moes ' $n$ regverdige aandeel in die land $\mathrm{kry}$. Om dit te bewerkstellig wyk hy van die tradisionele stamindeling af en maak 'n totaal nuwe indeling. In die sentrum sou die tempel staan en die Sadokiete die nuwe magsfigure wees. Van nou af sou alles om die tempel en die priesters draai. En die vors? Hy sou op 'n klein stukkie grond leef en sekere kleinerige takies vervul. Kortom: Israel sou mettertyd so ontnugter word in politieke mag dat van koningsmag geen sprake meer sou wees nie ${ }^{26}$.

\section{DEUTEROJESAJA: JAHWE IS DIE NUWE KONING}

Deuterojesaja (Jes 40-55) het 'n nuwe siening van mag geformuleer. Dinkwerk hieroor het waarskynlik in die Deuterojesajagroep plaasgevind. By die agste-eeuse Jesaja het hulle die verskrikking van menslike mag leer 
ken. By hierdie "ou profeet" het die noodlottige band tussen mag en godsdiens, magsoptrede van die staat en religieuse legitimering duidelik geblyk. Maar die Deuterojesajagroep het ook die Dawidiese koningsteologie geërf. En hiermee moes hulle inderdaad erns maak. Tipies van Israel se geskiedsdenke was die herinterpretasie van ou denke of tradisies. Deur herinterpretasie kon sin vir die hede ontgin word. Gevolglik is die nuwe element in Israel se teologie net 'n ander interpretasie (of lesing) van 'n ou tradisie. So was dit ook met die Deuterojesajagroep gesteld. Aan die ou koningsteologie het hulle net 'n ander interpretasie geheg. Dit is so omgebuig dat Jahwe die "nuwe koning" geword het. Hy het as 't ware die plek van die Dawidiese koning ingeneem. Hy is die Een wat op die troon van Sion sit en oor Israel regeer. Hy word ook "die Koning van Jakob" (Jes 41:21), “die Koning van Israel” (Jes 44:6), "julle Koning” (Jes 43:15) genoem $^{27}$.

Klem op Jahwe se koningskap het 'n drieërly effek gehad. Eerstens is politieke magstrewe hok geslaan. Anders gestel: enige magspoging van die ballinge is in die kiem gesmoor. Daarmee is die Ou-Nabye-Oosterse siening dat 'n god sy mag deur die koning en die staat reflekteer, vernietig. Tweedens, militêre mag is aan bande gelê. Dawidiese konings was nie meer nodig om Jahwe se stryd te stry nie. Jahwe doen dit sommer self. Omdat Hy koning is, onderwerp Hy sommer self die Babiloniërs en gebruik Kores vir sy doel. Derdens, die koning en Israel se "wêreldrol" is drasties ingekort. Volgens Psalm 72:8-11 regeer die koning nog van see tot see, van die Eufraat tot in die verste lande, kniel woestynbewoners voor hom, bring ander konings geskenke, betaal baie lande belasting. Kortom: "Mag alle konings voor hom buig en al die nasies hom dien" (Ps 72:11). Hierdie belangrike rol het die koning en die volk verbeur ${ }^{28}$.

Israel het egter ook nog 'n belangrike funksie vervul. Hulle moes net op 'n ander manier optree. Magsbeheptheid, magspeletjies en magsoptrede moes ten alle koste vermy word. Sonder eiebelang en dwang moes hulle optree. 'n Uitstekende voorbeeld was die lydende kneg volgens Jesaja 52:13-53:12. Israel moes sy taak nie met mag, grootpraat, verwaandheid en eiewaan vervul nie, maar in diepe nederigheid. Deur nikswees en lyding moes Israel sy roeping vervul29.

\section{1 'N SLOTWOORD}

Gesprekke oor kerkeenheid en die totstandkoming van 'n Verenigde Nederduitse Gereformeerde Kerk moet ook op "mag” fokus. Sommige van die gespreksgenote ervaar vir die eerste keer die soete smaak van politieke 
mag. Vir hulle is dit die vervulling van die Skrifte. God het oor ongeregtigheid getriomfeer en geregtigheid laat geskied. Politieke heerskappy is 'n gawe van God en iets wat gekoester moet word. Religieuse legitimasie van die staatsmag is daarom doodnatuurlik. Andere weer is sat van politieke mag. Hulle is ontnugter in politici en onvergenoegd met die hele politieke bedryf. Dikwels is mag misbruik en is die kerk op sleeptou geneem. Daarom wek "mag" by vele 'n gevoel van onbehaaglikheid. In die lig hiervan die volgende:

* Mag soek religieuse begronding. Dít bemagtig leiers en bedek vele misdrywe. Daarom die duidelike tendens in die Ou Testament om mag en godsdiens te skei. Met die val van Jerusalem en die daaropvolgende ballingskap het die noodlottige band tussen staatsmag en godsdiens die duidelikste geblyk. Oor mag en godsdiens sou mense mettertyd anders dink. Anders gestel: politieke mag het nie meer so 'n belangrike waarde gehad nie. In al die na-eksiliese HOP (vgl Deuterojesaja, Esegiël) sou staatsmag tot die minimum beperk word. Een denkrigting het eerder onmag, nederigheid, barmhartigheid beklemtoon. Vanweë die suur ervarings met sosio-politieke mag is dit uit die toekomsdrome verwyder. Gesprekke oor 'n Verenigde Nederduitse Gereformeerde Kerk moet goed oor politiek en godsdiens nadink.

* Gespreksgenote moet sensitief vir die fynvorme van magsmanipulasie wees. In elke gespreksgeleentheid (ook tussen die verteenwoordigers van die NG-Kerk-familie) is magsmanipulasie aan die werk. Ter illustrasie let ons op die apartheidsgeskiedenis. Elke interpretasie van die verlede dien 'n bepaalde groep se belange. Dit verleen legitimiteit aan groepsregte en is 'n uitstekende manipuleringsinstrument. Anders gestel: een groep trag om die mandaat of alleenreg op ' $n$ bepaalde interpretasie van die apartheidsverlede te kry. So word die groep bemagtig en kan hy sekere korttermyndoelwitte bereik. Sulke magspeletjies maak egter die geskiedenis dood.

* 'n Bepaalde Calvinistiese gedagterigting dat 'n Christen wêreldoorwinnend elke sektor van die samelewing (en veral die politiek) onder die gesag van Christus moet bring, is òf gedateer òf moet radikaal heraangepas word. Hierdie siening het die Afrikaner sleg getref. So is 'n deur vir die kerklike legitimering van politieke magspeletjies geopen. Dít het ons uiteindelik suur bekom. 'n Dure les is hierdeur geleer: dis nie die kerk of die godsdiens wat die spel dikteer nie, maar dis andersom. Eintlik speel die politiek die deuntjie en die kerk dans daarvolgens. 
* In hierdie tydsgewrig kan die "leer van die tweeryke" 'n moontlikheid bied ${ }^{30}$. Hiervolgens is daar twee ryke: hierdie wêreld, maar ook 'n ander een. Daar is die wêreld van mag en religieuse legitimering, politiek en ekonomie, magspeletjies en magsmanipulasie, propaganda en beheer. Dan is daar ook 'n ander wêreld: 'n wêreld van genade, sondevergifnis, ewige heil. 'n Ruimte waarin onmag, nederigheid, nikswees belangrik is. Waar mense bid, God ervaar en vir mekaar lief is. Waar mense na 'n ander wêreld van vreugde en blydskap uitsien. Hierdie wêreld is net so 'n werklikheid as die politiek-ekonomiese wêreld. Albei "ryke", dié van die wêreld en dié van kerk, is terreine waarin God werk. Hy is die Heer van albei wêrelde.

Tog staan albei teenoor mekaar: "Het ene rijk is het andere niet" 31 . Van vermenging is geen sprake nie. Beide 'ryke' moet voortdurend op gespanne voet met mekaar verkeer. So leer die kerk sy plek ken. Kerke beskik geensins oor die vermoë om met gesag in die sosio-politieke wêreld op te tree nie. Predikante se opleiding makk ook nie vir indringende sosiopolitieke opleiding voorsiening nie. Daar is andere wat die taak net baie beter as die kerk kan uitvoer. Dalk is die kerk nie meer op hierdie terrein nodig nie. Of anders gestel: dalk word die kerk nie eintlik in die wêreld gemis nie.

'n Winspunt van die "tweeryke-kyk" op die werklikheid is die herontdekking van die kerk se identiteit. In die nuwe Suid-Afrika is die kerk geen noodsaaklike sosio-politieke rolspeler meer nie. Indien die kerk van die toneel sou verdwyn, sal dit waarskynlik nie veel rimpels veroorsaak nie. Sosio-politieke magte en ekonomiese kragte is in beheer en sal ongeag die kerk net voortgaan. Vir die kerk is daar net een uitweg: word die ruimte van die swakkes, die onmagtiges, die ontnugterdes. Om 'n beeld uit die vroeë kerk te gebruik: die kerk is die moeder aan wie se borste (dit is die Ou en Nuwe Testament) haar kinders (die gelowiges) drink. In die "moederkerk" moet die wat ween getroos en die wat honger en dors het, versadig word. Dus: in plaas van 'n sosio-politieke rol moet die Verenigde Nederduitse Gereformeerde Kerk eerder 'n moedergestalte aanneem. Só kan die kerk weer 'n onmisbare plek inneem.

\section{NOTAS:}

1 Vergelyk H Graf Reventlow, "The role of the Old Testament in the German liberal Protestant theology of the nineteenth century", in: Biblical Studies and 
the shifting of paradigms (Edited by H Graf Reventlow \& W Farmer) Sheffield $1995,132-148$.

2 F A Van Jaarsveld, Die beeld van die Groot Trek in die Suid-Afrikaanse Geskiedskrywing 1843-1899, Pretoria 1963; F A Van Jaarsveld, “Oor vertolking en hervertolking in die geskiedskrywing”, in: Die hervertolking van ons geskiedenis, (F A Van Jaarsveld \& Theo van Wijk) Pretoria 1963, 7-26; F A Van Jaarsveld, The Afrikaner's interpretation of South African history, Cape Town 1964; F A Van Jaarsveld, Moderne geskiedskrywing, Durban 1982, 69112; F A Van Jaarsveld, Omstrede Suid-Afrikaanse verlede, Johannesburg 1984, 1-7; A van Niekerk, Rasionaliteit en relatiwisme, Pretoria 1992, 26-32, 52-60.

3 R Albertz, Religionsgeschichte Israels in alttestamentlicher Zeit, Vol 1-2, Göttingen 1992, 17-43.

4 J H le Roux, “'n Nuwe godsdiensgeskiedenis van Israel”, Ned Geref Teologiese Tydskrif (ter perse).

$5 \quad$ Albertz, $a w, 37-38$

6 H M Kuitert, Alles is politiek maar politiek is niet alles, Baarn 1986, 135,137.

$7 \quad$ Albertz, $a w, 76-85$.

$8 \quad$ Albertz, $a w, 58-68$.

9 R de Vaux, The early history of Israel, London 1978, 775-824.

10 A D H Mayes, "The period of the Judges and the rise of the monarchy", in: Israelite and Judaean history (Edited by John H Hayes \& J Maxwell Miller), London 1977, 308-322.

$11 \quad$ Albertz, $a w, 106-142$.

$12 \mathrm{H}$ Donner, Geschichte des Volkes Israel und seiner Nachbarn in Grundzügen, Göttingen 1984, 169-194.

13 Donner, $a w, 195-229$.

$14 \quad$ Albertz, $a w, 160-172$.

15 Albertz, $a w, 174-212$.

16 Albertz, $a w, 263$.

17 Miller \& Hayes, $a w, 323-326$. 
18 Miller \& Hayes, $a$ w, 340-346.

19 Miller \& Hayes, $a$ w, 346-364.

20 Albertz, a w, 254-255, 263-264.

21 A Deissler, Zwölf Propheten, Würzburg 1981, 9-11; J Limburg, Hosea-Micah, Louisville 1988, 38-47.

22 Vergelyk H D Preuss, Theologie des Alten Testaments, Vol I, Stuttgart 1991, 31-42.

23 Albertz, $a w, 264-274$.

24 Albertz, $a w, 348-360$.

25 Albertz, a w, 453-459.

26 J Blenkinsopp, Ezekiel, Louisville 1990, 222-227.

27 Albertz, $a$ w, 432-436.

$28 \quad$ Albertz, $a w, 431-446$.

29 P D Hanson, Isaiah 40-66, Louisville 1995, 153-169.

$30 \quad$ Kuitert, $a w, 141-153$.

$31 \quad$ Kuitert, $a w, 147$. 